Marquette University

e-Publications@Marquette

Economics Faculty Research and Publications

Economics, Department of

$1-1-2013$

\title{
Intertemporal Valuation of River Restoration
}

Andrew G. Meyer

Marquette University, andrew.g.meyer@marquette.edu

Accepted version. Environmental and Resource Economics, Vol. 54, No. 1 (January 2013): 41-61. The final publication is available at Springer via DOI. (C) 2013 Springer. Used with permission.

Andrew Meyer was affiliated with Ohio Wesleyan University at the time of publication.

Shareable Link. Provided by the Springer Nature SharedIt content-sharing initiative. 


\title{
Intertemporal Valuation of River Restoration*
}

\author{
Andrew Meyer ${ }^{\dagger}$
}

July 3, 2012

*This work was supported by the STC program of the National Science Foundation via the National Center for Earth-surface Dynamics under the agreement Number EAR- 0120914.

$\dagger$ Assistant Professor, Department of Economics, Ohio Wesleyan University, 61 S. Sandusky St., Delaware, OH 43015. email: agmeyer@owu.edu 


\begin{abstract}
Willingness to pay for an environmental improvement is a function of how long it takes to deliver the improvement. To measure the effect of time on benefits, I utilize a discrete choice experiment that includes an attribute for delay until the improvement occurs and simultaneously estimate discount rates and valuation parameters. I estimate the present value of immediate and delayed Minnesota River Basin improvements using discount rates directly estimated from the econometric model. Compared to an immediate river basin cleanup, Minnesota residents lose almost half of the benefits when cleanup is delayed by five years.
\end{abstract}

JEL Codes: D90, Q25, Q51, H43

Keywords: non-market valuation, intertemporal choice, discounting, water pollution 


\section{Introduction}

In recent years, discrete choice experiments (DCE's) have gained popularity for the valuation of environmental improvements. However, most of these studies fail to take into account a fundamental characteristic of the improvement; that is the timing of the benefits and costs of the improvement. This is not a trivial matter since delays as short as several years can make big differences in individuals' WTP. In light of this, I explicitly incorporate time until the improvement occurs as an attribute of the choice alternative. I can then calculate how much benefit is lost when restoration projects are delayed under various discounting assumptions including exponential, hyperbolic, and quasi-hyperbolic specifications.

According to the EPA's 2002 National Water Quality Inventory (2008), over 48 percent of the United States' assessed mileage of rivers and streams is classified as impaired or threatened. Agriculture is listed as the leading source of impairment, followed by other unknown nonpoint sources. Because of the nature of nonpoint pollution sources, it necessarily takes time to improve the environmental quality of a watershed. For example, there is a lag between when a pollutant is applied to a field and when the pollutant reaches the surface water body. Or, riparian buffer zones may have potential to remove up to 100 percent of incoming nitrate (Fennessy and Cronk, 1997), but it takes time to restore such a functioning zone where they are currently absent. Thus, it could be misleading to model the execution of a river cleanup as occurring today. Specifically, the present value of river restoration could be overestimated if the time dimension of the cleanup is ignored.

A stated preference survey concerning cleanup options for the Minnesota River Basin (MRB) was administered to Minnesota residents to gain insight into Minnesota residents' time preferences for environmental improvements. Based on this data, I simultaneously estimate discount rates and valuation parameters using the random utility theoretic framework developed in Meyer (2012). ${ }^{1}$ Here, I build on Meyer (2012) by examining welfare implications and estimating specifications that model heterogeneity in utility based on observable respondent characteristics. Since small changes in discount rates can often lead to large changes 
in present values, it is preferable to estimate discount rates within the context of the application at hand when conducting welfare analysis. This is an improvement over studies that first estimate valuation parameters and then later use researcher-imposed discount rates to calculate the present value of benefits.

I find that individuals discount their valuation of a cleanup of the MRB at a mean annual rate of thirteen percent. That is, individuals are willing to pay thirteen percent less for the same environmental improvement when the improvement is delayed by one year. I find evidence of significant heterogeneity in exponential discount factors and find some evidence that this heterogeneity can be explained by several observable individual characteristics. Residents of the MRB are less patient than nonresidents in the context of MRB improvements. There is weaker evidence that males are more patient than females and that discount rates decrease with education level. I also find evidence of significant heterogeneity in individuals' marginal valuations of basin improvement both from a random coefficients specification and from specifications that interact basin improvements with personal characteristics. Individuals with higher incomes and younger individuals display a higher marginal WTP for basin improvements. Additionally, in light of the recent research by Daly et al. (2012), I employ a bounded triangular distribution for the cost parameter to ensure that the WTP distribution exists.

A five year delay in basin cleanup leads to a 45 percent loss in marginal benefits compared to an immediate cleanup for identical levels of water quality improvement under the assumption of exponential discounting. While the survey sample is not representative of the Minnesota population, the summary characteristics of the sample are quite similar to the overall Minnesota population in many categories and there is substantial variation in the demographics of the survey participants. Thus, policy makers can gain some insight into how public support may change for alternative public policies with differing time dimensions.

Economists have noted the dilemma that exponential discounting poses for cost benefit analysis of distant future events. ${ }^{2}$ Essentially, events far in the future do not matter much 
when exponential discounting is utilized. However, an analysis of various discounting specifications in this context of river basin improvement over a short-term time horizon leads to very similar conclusions across the models.

\section{Previous Literature}

Stated preference approaches have previously been used to estimated the value of use and non-use benefits from ecosystem services. A 1999 survey article by Wilson and Carpenter (1999) summarizes the work in river and lake ecosystem valuation that was completed prior to 1997. Flores and Shafran (2007) update Wilson and Carpenter's work by summarizing studies completed since 1997. In this section, I focus on DCE's since they are most directly related to this research.

DCE's have been used to value water quality in several published studies. Whitmore and Cavadias (1974) estimate preferences for improving water quality in a Canadian community. Smith and Desvousges (1986) value water quality improvements of the Monongahela River in Pennsylvania. Magat et al. (2000) value increases in water quality for hypothetical rivers and lakes using an iterative approach and don't find any evidence of diminishing returns to improved water quality. That is, it appears that there is little harm in modeling preferences with a constant marginal utility of water quality improvement. Benefits are estimated in Magat el al. (2000) on an annual basis but temporal considerations are not addressed. Farber and Griner (2000) survey residents of a degraded watershed in Western Pennsylvania and utilize a DCE to value improvements in the watershed. The questions are worded so that WTP is interpreted as a per year measure with a duration of five years. However, no discounting is used in the analysis to convert the sum of five annual payments into a present value. Collins et al. (2005) estimate the economic values of improving aquatic life, scenic quality, and swimming in a West Virginia creek using a DCE. They estimate benefits per month but do not attempt to aggregate benefits across time. 
While there is a wide range in the methods utilized in previous studies, a common characteristic is that the time dimension of ecosystem improvements is largely ignored. One notable exception is the experimental design utilized by Viscusi, Huber, and Bell (2008). They estimate WTP for a water quality improvement as a function of the time until the improvement occurs.

Although the time dimension of ecosystem improvements is often ignored, there is a line of literature that has utilized stated preference methods to estimate discount rates in the context of mortality risk reductions and the VSL. Alberini et al. (2006) utilize a survey with a dichotomous choice response format to find an estimated discount rate of around 5.5 percent for Americans and 8.6 percent for Canadians. They do not find any significant relationship between personal characteristics and the discount rate except for nationality. Alberini and Chiabai (2007) use a dichotomous choice response format to estimate a discount rate of 0.31.7 percent in a similar VSL context in Italy. They also find a discount rate of 8.7 percent for money versus money tradeoffs.

Rheinberger (2011) estimates the VSL in the context of risk reductions on Alpine Roads using a DCE and find a discount rate around 11 percent. Rheinberger assumes that discounting is exponential and does not investigate heterogeneity in discounting behavior as the study is more concerned with risk parameters. Alberini and Šcasný (2011) use a DCE on risk reduction profiles where the respondent answers for themselves or for their child. They include an attribute, "latency," that takes on values of $0,2,5$, or 10 years, which represents the delay until the risk reduction occurs. The discount rate is estimated close to zero with an insignificant t-test. They also assume that there is one discount rate for the model. Alberini et al. (2007) utilize a DCE in the context of the VSL where they include two dependent attributes: the delay until the risk reduction occurs and the duration of the risk reduction benefits (year). Heterogeneity in the discount rate is captured by modeling the discount rate as a function of observable personal characteristics. They find an average discount rate for future risk reductions of 7 to 9 percent depending on the specification. All 
of these aforementioned VSL studies assume exponential discounting.

Two recent papers utilize empirical models that are based on the contingent valuation method to estimate rates of time preference and WTP. Kovacs and Larson (2008) estimate household discount rates in the range of thirty percent from a valuation study of public open space in Portland, Oregon. They use a double-bounded, dichotomous choice WTP question where they include variation in the schedule of payment across respondents. Similarly, Bond, Cullen, and Larson (2009) find discount rates ranging from 23.1 percent to 79.55 percent by varying the payment schedule and benefits timing in a valuation study of endangered species protection. While these two studies do explicitly consider the time dimension of public goods valuation, they do not consider any discounting models other than the standard exponential model.

\section{Study Design}

\subsection{Description of the Minnesota River Basin Study Area ${ }^{3}$ and Regulatory Environment}

The Minnesota River is Minnesota's largest tributary to the Mississippi River. It flows from Big Stone Lake on the Minnesota / South Dakota border until it doubles the volume of the Mississippi at their confluence near St. Paul, Minnesota (see Figure 1). Approximately 16,770 square miles in area, the MRB surrounds the Minnesota River. Agriculture predominates as the main land use, comprising 92 percent of the basin's area. According to the Minnesota River Basin Information Page from the University of Minnesota, "agricultural activities in the basin produce about $41 \%$ of Minnesota's corn, $51 \%$ of its soybeans, $11 \%$ of its wheat, $41 \%$ of its hogs, $22 \%$ of its beef, and adds several billion dollars to state revenues" (2008). Thus, the basin is an especially productive agricultural area.

As is common for highly agricultural areas, there are elevated levels of nonpoint source pollutants in the MRB. According to the Minnesota River Data Center (2007) at Minnesota 
State University, Mankato, the Minnesota River is one of the most seriously polluted rivers in the state of the Minnesota and the United States. Excessive sediment and nutrients such as phosphorus and nitrogen adversely affect fish populations and aquatic plants by stimulating high levels of algal growth and reducing the amount of oxygen in the water. Also, extremely high levels of algal growth sometimes turn into algal blooms which release toxins in the water that kill aquatic organisms. Furthermore, high levels of nitrate, fecal coliform and mercury discourage recreational uses of the MRB and pose potential health risks for human populations. Nitrate can pollute ground water and if ingested can cause methomogobinemia (also referred to as blue baby syndrome). Over 90 percent of the streams monitored in the MRB have fecal coliform levels that are unsafe and mercury in the MRB is ingested by fish, sometimes making it unsafe to eat fish caught in the MRB. In a scientific study of the Lower Minnesota River, Balogh, Meyer, and Johnson (1997) find that the mercury loadings are mainly determined by runoff-driven sediment inputs and minimally influenced by point source inputs. Sediment runoff is higher in intensively cultivated areas such as the MRB than in more undisturbed ecosystems.

In addition to these localized environmental problems, the MRB water quality problems transfer to other downstream areas. Lake Pepin, downstream of the confluence of the Minnesota and Mississippi Rivers, is filling in with sediment at ten times the natural rate and over ninety percent of the sediment is attributable to the Minnesota River. Excess nitrates flow from the Minnesota River to the Mississippi River and finally to the Gulf of Mexico where depleted oxygen levels damage commercial shell fishing and the aquatic ecosystem in general.

All surface waters in Minnesota are legally protected for aquatic life and recreation. Regulations state that water quality should be able to maintain healthy, diverse and successfully reproducing populations of aquatic organisms, including invertebrates such as fish and should be suitable for swimming and other forms of water recreation. The Federal Clean Water Act requires the State of Minnesota to assess whether surface waters support their designated 
uses.

While it is true that states can designate other uses of surface waters, Minnesota's surface water quality rules dictate that, unless listed otherwise, all waterbodies are protected for aquatic life and recreation but not drinking water. As the rule is written, this also protects the waterbody for industrial use, agricultural uses, aesthetics and navigation, and "other uses." The vast majority of waterbodies in Minnesota fall into this category although there are 31 stream segments or lakes within the MRB that are protected as a source of drinking water as well as for aquatic life and recreation. ${ }^{4}$ Less than one percent of all waterbodies in Minnesota are classified as "limited resource value waters", which receive treated wastewater and have limited protection (MPCA). In the MRB, there are 16 stream segments, 8 marshes/sloughs/swamps, and many ditches currently listed as limited resource value waters. Thus, even if respondents are aware of these segments that would never be cleaned to the swimmable and fishable criteria, there is a small enough number of such segments that it should not detract from the plausibility of cleaning between fifty and seventy percent of the basin. ${ }^{5}$

Preliminary data from the MPCA suggest that only ten percent of reviewed lake acres and nine percent of reviewed stream miles in the MRB support all assessed uses, suggesting that approximately 90 percent of the basin is likely impaired. ${ }^{6}$ Once a stream section or lake is listed as impaired, the MPCA develops limits (Total Maximum Daily Loads or "TMDL's") on problem pollutants within the area. The MPCA establishes TMDL's such that the surface waters will support aquatic life and recreation and then develops plans for meeting the pollution limits. From the 2008 MPCA Impaired Waters Inventory, the MPCA listed 336 impaired stream sections or lakes in the MRB that still required a TMDL. There were an additional 85 impaired stream sections or lakes that had been listed as impaired but a TMDL study had been approved by the EPA. Finally, there were 87 stream sections or lakes that were impaired by multiple pollutants with at least one TMDL study plan approved by the EPA. In the 2006 MPCA Impaired Waters Inventory, there were 497 stream sections 
or lakes that still required a TMDL and zero stream sections or lakes with EPA-approved TMDL's. Thus, there was substantial progress in the assessment and planning stages leading up to the timing of the survey.

\subsection{Study Sample}

The MRB provides both use and nonuse values to residents of Minnesota and downstream Mississippi River states. For feasibility, this study concentrates on use and nonuse values for Minnesota residents only. ${ }^{7}$ In January of 2008 , I administered a stated preference survey concerning water quality improvements in the MRB using a survey research firm, Survey Sampling International (SSI). Individuals receive incentives for participating in SSI surveys. Approximately 250 Minnesota residents voluntarily accessed the survey via the internet and the survey was available to all Minnesota SSI panel members until the quota of 250 responses was met. ${ }^{8}$ Some individuals that accessed the survey didn't answer required questions and were subsequently dropped from the sample. I dropped all observations from individuals that omitted responses to any of the demographic questions. I also dropped all observations from individuals that omitted responses to more than five choice scenarios. ${ }^{9}$ After dropping these individuals, I was left with 237 usable surveys.

\subsection{Survey Instrument and Data}

The first portion of the survey provides background information about the location and sub-basins of the study area. This portion of the survey also asks about respondents' prior knowledge and use of the basin, as well as whether the respondent lives in one of the subbasins. To further establish context, the survey details the current environmental situation of the MRB. It also explains that all surface waters in Minnesota are legally protected by the Federal Clean Water Act and that Minnesota is required to assess whether water quality is sufficient for all water bodies in the basin. Additionally, the survey informs respondents that the Minnesota Pollution Control Agency is currently developing limits on pollutants in 
order to comply with the Clean Water Act. Including this information should help establish more credibility to the survey exercise and emphasize to respondents that their opinions may actually shape public policy.

After respondents are familiarized with the study area, they complete the DCE. I present each participant with eight different choice sets and they must select their most preferred option within each choice set. Within each choice scenario, respondents choose between two alternatives. Respondents are processing the given information and selecting the option that gives them the highest utility, consistent with how individuals make everyday decisions. Since there is no status quo option in this survey, I cannot identify total WTP. I can, however, estimate the WTP for an attribute change. I define three attributes of each hypothetical cleanup scenario of the MRB. The three attributes are "Percentage of Basin Cleaned," "Cost of the Policy per Year," and "Time When Cleanup is Fulfilled." Table 1 provides the attribute definitions and levels.

In selecting the levels for the attributes, one must take into consideration what respondents believe are credible values. "Percentage of Basin Cleaned" includes levels of fifty, sixty, and seventy percent. ${ }^{10}$ "Cost of the Policy per Year" includes levels of $\$ 100, \$ 200$, and $\$ 300$. This is the same range of costs selected by Viscusi et al. (2008). ${ }^{11}$ Finally, "Time When Cleanup is Fulfilled" includes levels of zero, one, two, three, four, and five years from now. I utilize six levels of the time attribute to provide sufficient variation to identify discounting parameters from the various discounting models. ${ }^{12}$

To facilitate valuation of the MRB, it is necessary to include cost as an attribute. I am able to estimate the marginal WTP for river basin improvements by examining the tradeoff that respondents are willing to make between the amount of the basin that is cleaned and the cost of the policy per year. Since costs are defined on a per-year basis, the marginal WTP measure derived from this study is also interpreted as a per-year estimate. A reflection of a common occurrence in the real world, the survey explains that there may be situations where water quality improvements do not occur until some time in the future even though 
taxes are raised immediately to pay for the policy. Respondents evaluate policies that would temporarily improve the MRB's water quality in order to identify discounting parameters.

I provide some clarifying points within the attribute section of the survey. These clarifiers are intended to minimize confounding factors in the survey design and establish a common reference point for all respondents. To minimize uncertainty in the receipt of the future reward, respondents are informed that future cleanups are just as certain as immediate cleanups. This should mirror reality because a law setting a future pollution tolerance is just as binding as a law setting an immediate pollution tolerance in the MRB. I state that the current situation of the MRB should be considered zero percent cleaned and that this means none of the surface waters meet the requirements to meet the Clean Water Act. This is a close approximation to the real world situation and serves to establish a common reference point. ${ }^{13}$ Finally, I explain the timing of the benefits and costs of two sample alternatives. The sample choice question from the survey is given in Table 2 and the subsequent explanation text and tables as they appear in the survey are shown after the sample question. Individuals indicated that they understood all of these nuances during pretests. ${ }^{14}$

Both of the unlabeled options can take on three levels of two attributes and six levels of one attribute. Therefore, there are $\left(\begin{array}{l}3 \\ 2\end{array}\right) *\left(\begin{array}{l}3 \\ 2\end{array}\right) *\left(\begin{array}{l}6 \\ 2\end{array}\right)=135$ possible choice sets, some of which would have clearly dominated choices. Thus, it is more efficient to estimate parameters from a design of fewer choice sets. One popular measure of design efficiency is D-error. I utilize a priori parameter estimates from Viscusi, Bell, and Huber as inputs to the SAS choiceff macro, which generates a choice design that minimizes D-error. ${ }^{15}$

To assure sufficient intertemporal variation, I generate 32 choice sets. I divide the choice sets into four different versions so that each respondent can avoid fatigue and only answer eight choice questions. The online survey automatically rotated participants through the four versions so that each choice question received the same number of responses.

The final portion of the survey collects demographic information. While the sample is not meant to be representative of the state of Minnesota, I observe variation in the answers to 
the demographic questions so that I am able to explore differences in water quality valuation for different subpopulations. This sample provides useful insights into the marginal tradeoffs that individuals are willing to make over time even though the WTP measures may differ from the median Minnesota citizen. I also use the demographics to investigate differences in discount factors based upon observable characteristics. Summary demographic information is presented in Table 5 .

As previously noted, this study yielded 237 usable surveys. After dropping blank responses from some individuals that did not answer all questions, I was left with data for 1819 choice occasions.

\section{Estimation Strategy and Results}

\subsection{Empirical Model}

To analyze discrete choice data, I employ a random utility theoretic framework. This framework explicitly accounts for the intertemporal nature of the choices. ${ }^{16} \mathrm{I}$ assume that intertemporal utility depends upon a deterministic portion and an error term that is unobservable to the researcher. Specifically, the intertemporal utility for individual $i$ and choice $j$ is given by

$$
U_{i j}=\sum_{t=0}^{T_{j}} \psi_{t} v_{i j t}+\epsilon_{i j}
$$

where $\epsilon_{i j}=\sum_{t=0}^{T_{j}} \psi_{i t} \eta_{i j t}$ is the error for individual $i$ associated with choice $j$, $\eta_{i j t}$ is the instantaneous error draw for individual $i$ associated with choice $j$ and time period $t, \psi_{t}$ is the discount factor at time $t, v_{i j t}$ is instantaneous utility, and $T_{j}$ is the last year of policy $j$. I assume that $\eta_{i j t} \sim N\left(0, \sigma^{2}\right)$. Absent any modifications, this in turn implies that error draws are independent across observations for a given decision maker, which is an unrealistic assumption given the panel nature of this data set. There are several approaches that one could take to build in error correlation across the utilities of different 
alternatives for one individual. In Meyer (2012), I show a how various random coefficients specifications can model this correlation. As discussed in Train (2003), random coefficients is formally equivalent to an error components model and both capture correlation of utilities over alternatives. In the preferred specification from Meyer (2012), discount factors and valuation parameters are treated as randomly varying across individuals.

I assume that $v_{i j t}$ depends upon individual $i$ 's income for time $t, Y_{i t}$, the level of river basin cleanup in time period $t, q_{i j t}$, the cost of the cleanup for time $t, c_{i j t}$, and $i$ 's random draws for the coefficients on $q$ and $c$. For the first specification, I have

$$
U_{i j}=\sum_{t=0}^{T_{j}} \psi_{i t}\left[\alpha_{i} q_{i j t}+\gamma_{i}\left(Y_{i t}-c_{i j t}\right)\right]+\epsilon_{i j} .
$$

Loosely following the exposition of Train (2003), $\alpha_{i}$ and $\gamma_{i}$ are fixed for an individual across choice occasions, but vary across individuals. Assume $\alpha_{i}$ is normally distributed in the population with mean $\bar{\alpha}$ and variance $z_{\alpha}^{2}$. Since one of the primary objectives of this research is to estimate mean MWTP $(-\alpha / \gamma)$, it is important to ensure that the mean of the WTP distribution exists. As shown by Daly et al. (2012), no WTP moments exist when an unbounded normal distribution is used for the distribution of the cost coefficient. However, mean WTP does exist for a triangular distribution that is bounded at 0 . Thus, I assume that $\gamma_{i}$ is distributed according to a triangular distribution with mean $\bar{\gamma}$ and spread $\bar{\gamma}$. By constraining the mean and spread to be equal, I can assure that the $\gamma$ coefficient has the same sign for all individuals. This is a desirable property because we would not theoretically expect any individuals to have positive price coefficients and because it bounds the distribution at 0 , ensuring the existence of mean WTP.

Furthermore, assume $\psi_{i}$ is fixed for an individual but distributed normally in the population with mean $\bar{\psi}$ and variance $z_{\psi}^{2}$. Denote the choice situation as $s$ and a sequence of alternatives as $\mathbf{j}=\left\{j_{1}, \ldots, j_{S}\right\}$. Then, conditional on $\alpha, \gamma$, and $\psi$, the probability that indi- 
vidual $i$ makes a sequence of choices is the product over all $s$ of the single choice probabilities:

$\mathbf{P}_{i \mathbf{j}}(\alpha, \gamma, \psi)=\prod_{s=1}^{S} F\left(\frac{\sum_{t=0}^{T_{j, s}} \psi_{i t}\left[\alpha_{i} q_{i j t s}+\gamma_{i}\left(Y_{i t s}-c_{i j t s}\right)\right]-\sum_{t=0}^{T_{k, s}} \psi_{i t}\left[\alpha_{i} q_{i k t s}+\gamma_{i}\left(Y_{i t s}-c_{i k t s}\right)\right]}{\sqrt{\sum_{t=0}^{T_{k, s}} \psi_{i t}^{2}+\sum_{t=0}^{T_{j, s}} \psi_{i t}^{2}}}\right)$.

Denote the vector for individual $i$ containing $\alpha_{i}, \gamma_{i}$, and $\psi_{i}$ as $\boldsymbol{\theta}_{i}$. Since the $\boldsymbol{\theta}$ are random, I integrate out over all values of $\boldsymbol{\theta}$ to get the unconditional choice probability

$$
P_{i \mathbf{j}}=\int \mathbf{P}_{i \mathbf{j}}(\boldsymbol{\theta}) f(\boldsymbol{\theta}) d \boldsymbol{\theta}
$$

I draw $R$ values of $\boldsymbol{\theta}$ and denote them $\boldsymbol{\theta}_{r}$. The simulated choice probability is $\widetilde{P}_{i \mathrm{j}}=$ $\frac{1}{R} \sum_{r=1}^{R} \mathbf{P}_{i \mathbf{j}}\left(\boldsymbol{\theta}_{r}\right)$. In this application, I set $R=200$. Finally, I insert these simulated choice probabilities into the log-likelihood function to get the simulated log likelihood (SLL)

$$
\mathrm{SLL}=\sum_{i} \sum_{\mathbf{j}} y_{i \mathbf{j}} \ln \widetilde{P}_{i \mathbf{j}}
$$

where $y_{i \mathbf{j}}=1$ if $i$ chose sequence $\mathbf{j}$ and zero otherwise.

I estimate the means and standard deviations of all random parameters. One limitation of assuming random parameters on the discount factor is that we do not see how personal characteristics correlate with time preferences. To answer this question, I also include Specification II where the discount factor is a function of personal characteristics. Personal characteristics that could potentially influence discounting behavior include age, income, sex, education level, and whether the respondent resides within the Minnesota River Basin. In the case of the exponential discounting model, $\delta=b_{0}+b_{1}$ age $+b_{2}$ income $+b_{3}$ male + $b_{4}$ education $+b_{5}$ resident. I then modify equation 3 by substituting $\delta$ for $\psi_{i}$. To test whether inclusion of demographics significantly improves model fit, I include a third specification identical to Specification II except that all demographic variables are assumed to have coefficients equal to 0. 
Likewise, a limitation of assuming random coefficients on the benefit and cost variables is that we do not see how one's marginal valuation changes with their personal characteristics. Therefore, I estimate two additional specifications where I still assume discounting parameters are randomly distributed across the population and fixed for one person. This ensures that utilities from different choice scenarios are still correlated for a given decision maker. One of the additional specifications includes interactions of the cost and benefit variables with personal characteristics and the other assumes these personal interactions are equal to 0 . Thus, for the fourth specification, I have

$$
U_{i j}=\sum_{t=0}^{T_{j}} \psi_{i t}\left[\alpha q_{i j t}+\gamma\left(Y_{i t}-c_{i j t}\right)+\lambda q_{i j t} x_{i t}+\xi c_{i j t} x_{i t}\right]+\epsilon_{i j}
$$

where $x_{i t}$ is a vector of personal characteristics for individual $i$ at time $t$.

\subsection{Results}

The format of the discount factors $\left(\psi_{t}\right)$ will depend on the type of discounting that is assumed. Since I show in Meyer (2012) that the exponential discounting model is preferred over hyperbolic discounting models for this data set, I take this as given. ${ }^{17}$ Thus, I assume that $\psi_{i t}=\delta_{i}^{t}=\frac{1}{\left(1+r_{i}\right)^{t}}$ where $\delta$ is the exponential discount factor and $r$ is the exponential discount rate. I focus here on deriving welfare implications and exploring the determinants of heterogeneity in the discount factor and WTP.

Table 6 presents simulated maximum likelihood results for Specification I; all coefficients

are highly significant. The ratio of $-\frac{\widehat{\alpha}}{\widehat{\gamma}}$ gives an estimate of the annual WTP for a one percent increase in the amount of river basin cleanup. Using the point estimates of the mean values from Table 6, annual WTP for an additional one percent of river basin cleanup is $\$ 8.86$ with a 95 percent confidence interval of $(\$ 5.97, \$ 11.75) .{ }^{18}$

For Specification II, coefficients on the means and standard deviations of improvement and cost remain highly significant. Resident is the only personal characteristic that is 
significant at the conventional levels. Two other personal characteristics are close to being significantly related to the discount factor. Male has a positive estimated coefficient with a p-value of 0.105 and Education has a positive estimated coefficient with a p-value of 0.118. Using the point estimates on Resident, Male, and Education, all else equal, MRB residents have an estimated discount rate that is about 5.2 percentage points higher than non-residents, males have an estimated discount rate that is about 3.9 percentage points lower than females and the estimated discount rate decreases by about 1.1 percentage points for each additional $\$ 15,000$ in gross household income. Since Specification III is a restricted version of Specification II, I utilize a likelihood ratio test. The null hypothesis of the test is that the coefficients of the personal characteristics are equal to zero; this corresponds to Specification III. I reject the null hypothesis that the effects of the personal characteristics are jointly equal to zero ( $\mathrm{p}$-value $=0.06$ ). Thus, there is evidence that MRB residents are less patient than non-residents and weak evidence that males may be slightly more patient than females and higher income individuals may be more patient for this population. ${ }^{19}$

In Specification IV, Cost, Improvement, and the mean and standard deviation of the discount factor remain significant at the 0.01 level. Only two of the coefficients on the personal interaction variables are significant at conventional levels. Both (Improvement $X$ Income)/10000 and (Improvement X Age)/1000 are significant at the 0.1 level. All else equal, individuals with higher incomes value basin water quality improvements more than those with lower incomes, as is expected. Interestingly, older individuals have a lower marginal utility of basin improvement. This could be due to older individuals being less inclined to do the activities that would derive use benefits from the basin or being less inclined to support environmental programs. Three other variables are quite close to being significant at the 0.1 level. (Improvement $X$ education) has a p-value of 0.112 , (Cost $X$ income) has a p-value of 0.109 , and (Cost X education) has a p-value of 0.106 . The nearly significant interactions suggest that people with more education value basin improvements less and higher income individuals are more sensitive to price. 
The coefficients on these marginally significant interaction variables do not agree with intuition so I run three other specifications as internal validity checks on the survey. In Specification VI I only interact the level of basin improvement with personal characteristics and in Specification VII I only interact the cost of the policy with personal characteristics. Specification V restricts all of the coefficients on personal interaction variables to be equal to 0 and is included for comparison purposes. Compared to Specification V, there is very little improvement in the maximized value of the simulated log likelihood equation in Specification VII. The improvement is a little better in Specification VI, but it is still a statistically insignificant improvement. That is, interactions of personal characteristics with benefit or cost alone are insignificant as measured by a likelihood ratio test. However, the dubious results from Specification IV on (Cost $X$ income), (Cost $X$ education), and (Improvement $X$ education) disappear in Specifications VI and VII, which is good from an internal validity standpoint.

To determine whether Specification IV or V is preferred, I utilize a likelihood ratio test. The null hypothesis of the test is that the coefficients of the personal interaction variables are equal to zero; this corresponds to Specification V. I fail to reject the null hypothesis that the personal interaction coefficients are jointly equal to zero. ${ }^{20}$ As a result, I rely on the results from Specification I for welfare analysis.

As the survey stated that cleanups would last for five years, the total discounted MWTP for an immediate river basin cleanup is equal to the present discounted value of all five years of benefits. That is, PVMWTP Pimmediate $=\left(1+\widehat{\delta}+\widehat{\delta}^{2}+\widehat{\delta}^{3}+\widehat{\delta}^{4}\right) *\left(-\frac{\widehat{\alpha}}{\widehat{\gamma}}\right)$. With the mean estimates from Specification I in Table 6, PVMWTP $P_{\text {immediate }}=\$ 35.38$ with a 95 percent confidence interval of $(\$ 23.60, \$ 47.16)$.

Now suppose that it takes five years for the river basin cleanup to occur. Then, the total discounted MWTP for the delayed river basin cleanup is equal to the present discounted 
value of the delayed benefits. That is,

$$
P V M W T P_{5 y \text { rdelay }}=\left(\widehat{\delta}^{5}+\widehat{\delta}^{6}+\widehat{\delta}^{7}+\widehat{\delta}^{8}+\widehat{\delta}^{9}\right) *\left(-\frac{\widehat{\alpha}}{\widehat{\gamma}}\right)
$$

Using the estimates from Table $6, P V M W T P_{5 y \text { rdelay }}=\$ 19.45$ with a 95 percent confidence interval of $(\$ 12.15, \$ 26.75)$.

Comparing $P V M W T P_{\text {immediate }}$ with $P V M W T P_{5 y r d e l a y}$, a delay of five years in the time that it takes to execute the river basin cleanup leads to a $45.03 \%$ loss in marginal WTP. In other words, respondents would be willing to pay the same amount for a $54.97 \%$ total cleanup of the Minnesota River Basin today as they would for a $100 \%$ total cleanup of the MRB that is delayed by five years. ${ }^{21}$

Lastly, I explore the sensitivity of the results for other discounting models. Here, I present estimation results only for the full random parameters models without specifying discounting parameters as a function of personal characteristics. ${ }^{22}$ Discount factors for Harvey's (1986) single-parameter hyperbolic structure are given by

$$
\psi_{t, \text { Harvey }}=(1+t)^{-\mu}
$$

In the single-parameter model suggested by Herrnstein (1981) and Mazur (1987) (HM), discount factors are

$$
\psi_{t, H M}=(1+\omega t)^{-1}
$$

Finally, in the quasi-hyperbolic model ${ }^{23}$, the functional form of discount factors is given by

$$
\psi_{t, Q-H}=\left\{\begin{array}{c}
1 \text { if } t=0 \text { and } \\
\beta \delta^{t} \text { if } t>0
\end{array}\right\} \text {, where } 0<\beta<1 \text {, and } \delta<1
$$

Table 8 shows the estimation results for three alternative discounting models. I assume the Harvey parameter, $\mu$, is distributed normally. For the HM Hyperbolic parameter, $\omega$, and 
the Quasi-Hyperbolic parameters, I assume lognormal distributions as a practical necessitation for convergence. Table 9 gives the means, medians, and standard deviations of these parameters. As is shown in Meyer (2012), the exponential model is preferred to both of the single parameter hyperbolic models and the quasi-hyperbolic model does not improve model fit enough to warrant its adoption over the exponential model.

Using the parameter estimates from Tables 8, I calculate point estimates of the mean amount individuals would be willing to pay today for immediate and delayed MRB cleanups for each of these alternative discounting specifications. Table 10 shows the present values of the average WTP for an immediate and a five year delayed one percent increase in basin cleanup for the alternative discounting models. One can see that the point estimates all fall within the confidence intervals from the exponential model.

From the point estimates of the present values of the MWTP for immediate and delayed cleanups, I calculate the estimated loss in marginal benefits for each of the alternative discounting models for comparison with the loss in marginal benefits under exponential discounting. The estimated lost marginal benefits for a cleanup that is delayed by five years is 41.7 percent for the Harvey Hyperbolic model, 38.4 percent for the HM Hyperbolic model, and 46.4 percent for the quasi-hyperbolic model. Thus, no matter which discounting model is fit in this application, the loss in marginal benefits is of similar magnitude.

Figure 2 plots discount factors for the four discounting models. In this figure, I use parameter estimates that are consistent with those found in this study for all discounting models. The HM discount factors track closely with exponential discount factors throughout the relevant time frame. The Harvey discount factors are slightly lower than the exponential discount factors until around year 9 when they cross. Also, the quasi-hyperbolic discount factor is always slightly above the exponential discount factor but follows the same general pattern. Therefore, it is not surprising that the MWTP confidence intervals overlap with these specific discounting parameters. In Figure 3 I use parameters that differ from the results of this study but that are still within the range discussed in the literature. ${ }^{24}$ In 
this case, the two single parameter hyperbolic discount factors diverge substantially from the exponential discount factor. The large initial drop in the hyperbolic discount factors graphed in Figure 3 captures the behavior of a present-biased individual. If individuals in this study truly exhibited discount factors such as those shown in Figure 3 I would expect those hyperbolic models to fit better than the exponential model, which cannot capture such present-biased behavior. In this case, I would also expect some divergence in the MWTP confidence intervals.

\section{Conclusion}

It often takes time to achieve environmental improvements, especially for nonpoint sources of pollution. Previous work has too often neglected this issue when estimating the benefits from an environmental policy. As a result, there is potential for the estimates reported in a typical study to overstate the true present value of benefits. For example, an overestimate would occur if respondents were not anticipating a delay in benefits while the researcher modeled a truly delayed outcome as though it were immediate. To address this issue, I include an attribute for delay until an improvement is executed in the discrete choice experimental design. I then simultaneously estimate discounting parameters and the coefficients on the amount of river basin improvement and annual cost of the improvement. This strategy produces estimates for the present value of immediate and delayed river basin improvements without having to separately impose a researcher specified discount rate.

Respondents of the Minnesota River Basin survey discount future basin water quality improvements at an annual rate of thirteen percent. This is lower than many experimental discounting studies but in line with results from many VSL studies. This implies that Minnesota residents lose almost half of the marginal benefits when improvements arrive five years from now instead of today. By recognizing the extent of the tradeoff between the level of environmental improvement and the delay until the improvement occurs, policy makers 
can evaluate how much individuals will support competing programs. On the other hand, policy makers that neglect information about this tradeoff could propose policies that will receive low levels of public support.

A limitation of this research is that the sample is limited in size and may not be representative of the population of Minnesota. Nevertheless, there is sufficient variation in demographics to analyze heterogeneity in both time preferences and the marginal utility of benefits and costs. Furthermore, a rule of thumb from marketing research suggests that I need approximately 1550 choices for the results to be reliable in terms of statistical power, which is less than the 1819 choices present in this sample (Hensher et al., 2005).

For events in the distant future, economists are often not comfortable with the use of exponential discounting because it places too low of a value on future environmental benefits. However, in this case, the hyperbolic models would lead us to weigh future marginal benefits no differently than the exponential model. This should give some comfort to researchers using exponential discount rates for cost benefit analysis of projects with a five or ten year timeframe. Furthermore, exponential discounting is statistically supported for the respondents of this survey, so it is appropriate to use constant discount rates to convert benefits into present values in this context anyhow.

Purely a descriptive study, I have not addressed the issue of how society as a whole should discount the future. I assume that individuals care only about their own utility and discount future benefits based upon these intertemporal preferences. This is a reasonable assumption for this study since the timeframe is relatively short and considerations for future generations are not relevant. However, it would be an interesting extension to model preferences in different manner for very long run issues such as climate change. A DCEwith time as an attribute could potentially address these types of issues. 


\section{Notes}

${ }^{1}$ Meyer (2012) develops the estimation strategy and exclusively focuses on testing various discounting models for 3 data sources: the Minnesota River Basin Survey, a stated preference monetary survey, and state lottery winners' choices between lump sum and annuity jackpots. The key finding of that paper is that exponential discounting is preferred to hyperbolic discounting when describing behavior for both the MRB study and lottery winners.

${ }^{2}$ See, for example, Weitzman $(2001 ; 2010)$.

${ }^{3}$ This description of the MRB borrows heavily from the description developed by Nicholas Flores for a different survey.

${ }^{4} \mathrm{I}$ do not distinguish in the survey between waterbodies that are or are not protected for drinking water because there are a relatively small number of segments protected for drinking water in the MRB and a uniform criteria on all segments gives the percentage figure more meaning.

${ }^{5}$ For more information on the Minnesota surface water regulations, see Minnesota Rules Chapter 7050, available at https://www.revisor.mn.gov/rules/?id=7050, and the explanation of the rules provided by the MPCA (MPCA).

${ }^{6}$ The MPCA does note that reviewed waters reflect efforts in past years to monitor and assess more waters where problems were thought to exist in order to increase the likelihood they would be worked on sooner. These percentages are therefore not necessarily reflective of total impaired water percentages basin wide. Minnesota has initiated an intensive watershed monitoring design that is more systematic and unbiased.

${ }^{7}$ While I do not distinguish between use and nonuse values in the survey questions, I do collect information about whether respondents reside within the MRB. As shown in the results, being a resident of the study area has no significant explanatory power over the MU of improvement or cost. This suggests that use and nonuse values are similar in magnitude.

${ }^{8} \mathrm{I}$ am not able to determine how many potential respondents saw the opportunity to complete the survey and subsequently declined to participate. However, the survey opened 
at 8:00 am on a Monday morning and had reached the quota of 250 respondents by Thursday morning of that same week. Each SSI panelist was assigned a unique ID to prevent multiple survey responses from the same person.

${ }^{9}$ Two individuals completed three choice scenarios, two completed four choice scenarios, three completed five scenarios, ten completed six scenarios, thirty completed seven scenarios, and 190 completed all eight scenarios. Estimation results are not sensitive to the exclusion of the individuals who completed three or four choice scenarios.

${ }^{10}$ There is an efficiency gain in choosing attribute levels for quantitative factors that are spread wider apart from one another. While a fifty percent improvement is large for a relatively short timeframe, focus groups indicated that improvements close to 0 percent were viewed quite differently than improvements of more than fifty percent. Similarly, improvements of 100 percent were potentially viewed differently than improvements of 50 percent. As I planned to model utility as linear in percentage of basin improvements, I wanted to avoid introducing potential nonlinearlities in this attribute due to including levels below 50 percent or too close to 100 percent. Since the discount rate is being identified from tradeoffs in the extent of the basin improvement, it is critical to stay within a linear improvement range.

${ }^{11}$ Further ameliorating concern over sensitivities to the cost levels chosen, Hanley, Adamowicz, and Wright (2005) find no significant difference in estimates of preferences or willingnessto-pay when changing the price levels.

${ }^{12}$ There is a tradeoff here between selecting cleanup timeframes that are plausible to the respondents and getting enough intertemporal variation to identify the parameters of various discounting specifications. I am working under the assumption that respondents can abstract from the reality of time lags and imagine that the MRB were "magically" cleaned to the specified level with no or little delay when indicated by the choice scenario.

${ }^{13}$ Recall that a preliminary measure from the MPCA suggests that approximately ten percent of the basin is currently supporting all assessed uses. Anecdotal evidence from 
scientists at the time of survey administration supported the approximation of zero percent meeting requirements of the Clean Water Act.

${ }^{14}$ One concern related to using a forced choice survey design is that total WTP values can be biased upwards because some individuals that would vote "no" to all alternatives are still forced to choose one of the alternative improvement policies, even if it would lead to a net loss in utility. However, "if an opt-out alternative is not presented, the choice provides information on preferences, conditional on choosing one of the alternatives, but it does not provide information on whether the individual would choose one of the alternatives or not" (Holmes and Adamowicz, 2003). Viscusi et al. utilize a forced choice design in a similar context and find that "water quality-cost tradeoffs were similar to those using a referendum format and an iterative paired comparison format" (2008). This coupled with concerns about having sufficient statistical power to facilitate testing between competing discounting hypothesis with a reduced sample size led to the decision to omit an "opt-out" alternative. Therefore, I only estimate marginal WTP for this study.

${ }^{15}$ D-efficiency sacrifices some design orthogonality through using prior information about parameters to ultimately result in data that generates smaller standard errors on parameter estimates.

${ }^{16}$ For further details of the development of the model, see Meyer (2012).

${ }^{17}$ The exponential model is preferred to the quasi-hyperbolic model on the basis of a likelihood ratio test and is preferred to the single parameter hyperbolic models on the basis of non-nested model selection tests such as the AIC.

${ }^{18}$ The confidence intervals in this section are constructed using the delta method.

${ }^{19}$ The test statistic is equal to twice the difference in the maximized values of the simulated $\log$ likelihoods corresponding to the two specifications and is distributed chi-squared with 5 degrees of freedom. From Table 6, the test statistic is equal to 10.57.

${ }^{20}$ The test statistic is equal to twice the difference in the maximized values of the simulated log likelihoods corresponding to the two specifications and is distributed chi-squared with 
ten degrees of freedom. From Table 6, the test statistic is equal to 13.121.

${ }^{21}$ This assumes a constant marginal utility of basin improvement over the relevant range of cleanup possibilities.

${ }^{22}$ For each of the alternative discounting models, I fail to reject the null hypothesis that coefficients on the personal characteristics are equal to zero. These results are available upon request.

${ }^{23}$ The quasi-hyperbolic functional form was first introduced by Phelps and Pollak (1968). Laibson (1997) applied the functional form to consumption and savings decisions.

${ }^{24}$ See, for example, Keller and Strazzera (2002); Viscusi et al. (2008); Cairns and van der pol (2000).

\section{References}

Agency, U.E.P., 2008. Monitoring and assessing water quality. available at http://www.epa.gov/305b/.

Alberini, A., Chiabai, A., 2007. Discount rates in risk versus money and money versus money tradeoffs. Risk Analysis 27, 483-498.

Alberini, A., Cropper, M., Krupnick, A., Simon, N.B., 2006. Willingness to pay for mortality risk reductions: Does latency matter?. Journal of Risk and Uncertainty 32, 231 - 245 .

Alberini, A., Scasny, M., 2011. Context and the vsl: Evidence from a stated preference study in italy and the czech republic. Environmental and Resource Economics 49, 511 - 538.

Alberini, A., Tonin, S., Turvani, M., Chiabai, A., 2007. Paying for permanence: Public preferences for contaminated site cleanup. Journal of Risk and Uncertainty 34, 155 - 178.

Balogh, S.J., Meyer, M.L., Johnson, D.K., 1997. Mercury and suspended sediment loadings in the lower minnesota river. Environmental Science and Technology 31, 198-202. http://pubs.acs.org/doi/pdf/10.1021/es960327t. 
Bond, C.A., Cullen, K.G., Larson, D.M., 2009. Joint estimation of discount rates and willingness to pay for public goods. Ecological Economics 68, 2751-2759.

Cairns, J., van der Pol, M., 2000. Valuing future private and social benefits: The discounted utility model versus hyperbolic discounting models. Journal of Economic Psychology 21, 191-205.

Center, M.R.B.D., 2007. Minnesota river basin data center. available at http://mrbdc.mnsu.edu/.

Collins, A., Rosenberger, R., Fletcher, J., 2005. The economic value of stream restoration. Water Resources Research 41. NU: Citation No. W02017; TR: CS0507258.

Daly, A., Hess, S., Train, K., 2012. Assuring finite moments for willingness to pay in random coefficient models. Transportation 39, $19-31$.

Farber, S., Griner, B., 2000. Valuing watershed quality improvements using conjoint analysis. Ecological Economics 34, 63-76.

Fennessy, M.S., Cronk, J.K., 1997. The effectiveness and restoration potential of riparian ecotones for the management of nonpoint source pollution, particularly nitrate. Critical Reviews in Environmental Science and Technology 27, 285-317. http://www. tandfonline.com/doi/pdf/10.1080/10643389709388502.

Flores, N.E., Shafran, A., 2007. What we know about valuing ecosystem improvements and restoration.

Hanley, N., Adamowicz, W., Wright, R.E., 2005. Price vector effects in choice experiments: An empirical test. Resource and Energy Economics 27, $227-234$.

Harvey, C.M., 1986. Value functions for infinite-period planning. Management Science 32, $1123-1139$. 
Hensher, D.A., Rose, J.M., Greene, W.H., 2005. Applied Choice Analysis: A Primer. Cambridge and New York:

Herrnstein, R., 1981. Self-Control as Response Strength. Elsevier/North-Holland, New York. Quantification of Steady-State Operant Behavior, pp. 3-20.

Holmes, T.P., Adamowicz, W.L., 2003. A Primer on Nonmarket Valuation: Attribute-Based Methods.. Economics of Non-market Goods and Resources, vol. 3., Southern Research Station, US Forest Service. pp. $171-219$.

Keller, L.R., Strazzera, E., 2002. Examining predictive accuracy among discounting models. Journal of Risk and Uncertainty 24, 143-160.

Kovacs, K.F., Larson, D.M., 2008. Identifying individual discount rates and valuing public open space with stated-preference models. Land Economics 84, 209-224.

Laibson, D., 1997. Golden eggs and hyperbolic discounting. Quarterly Journal of Economics $112,443-477$.

Magat, W.A., 2000. An iterative choice approach to valuing clean lakes, rivers, and streams. Journal of Risk and Uncertainty 21, 7-43.

Mazur, J.E., 1987. An Adjustment Procedure for Studying Delayed Reinforcement. Erlbaum, Hillsdale, NJ. Quantitative analysis of behaviour: The effect of delay and intervening events on reinforcement value, pp. 55-73.

Meyer, A.G., 2012. Estimating Discount Factors for Public and Private Goods and Testing Competing Discounting Hypotheses. SSRN eLibrary .

MPCA, Water quality standards. available at http://www.pca.state.mn.us/index.php/water/water-monitoring-and-reporting/waterquality-and-pollutants/water-quality-standards.html. 
Page, M.R.B.I., 2008. Minnesota river basin information page: Department of soil, water, and climate, university of minnesota. available at http://www.soils.umn.edu/research/mnriver/.

Phelps, E.S., Pollak, R.A., 1968. On second-best national saving and game-equilibrium growth. The Review of Economic Studies 35, 185-199.

Rheinberger, C.M., 2011. A mixed logit approach to study preferences for safety on alpine roads. Environmental and Resource Economics 49, 121 - 146.

Smith, V.K., Desvousges, W.H., 1986. Measuring Water Quality Benefits. Kluwer, Boston.

Train, K.E., 2003. Cambridge University Press, New York, NY. Discrete Choice Methods with Simulation.

Viscusi, W.K., Huber, J., Bell, J., 2008. Estimating discount rates for environmental quality from utility-based choice experiments. Journal of Risk and Uncertainty 37, 199-220. RX: 850816 (on May 24, 2010).

Weitzman, M.L., 2001. Gamma discounting. The American Economic Review 91, 260-271.

Weitzman, M.L., 2010. Risk-adjusted gamma discounting. Journal of Environmental Economics and Management 60, $1-13$.

Whitmore, G.A., Cavadias, G.S., 1974. Experimental determination of community preferences for water quality-cost alternatives. Decision Sciences 5, 614-631.

Wilson, M.A., Carpenter, S.R., 1999. Economic valuation of freshwater ecosystem services in the united states: 1971-1997. Ecological Applications 9, 772-783.

[Figure 1: The Minnesota River Basin]

[Figure 2: Comparison of Discount Factors I: Exponential $\left(\delta^{t}\right)$ with $\delta=.887$, Harvey Hyperbolic $\left((1+t)^{-\mu}\right)$ with $\mu=.459$, Quasi-hyperbolic $\left(1, \beta \delta^{t}\right)$ with $\beta=$ 1.099, $\delta=.879$, and HM Hyperbolic $\left((1+\omega t)^{-1}\right)$ with $\left.\omega=.156.\right]$ 
[Figure 3: Comparison of Discount Factors II: Comparison of Discount Factors II: Exponential $\left(\delta^{t}\right)$ with $\delta=.885$, Harvey Hyperbolic $\left((1+t)^{-\mu}\right)$ with $\mu=.6$, Quasi-hyperbolic $\left(1, \beta \delta^{t}\right)$ with $\beta=.7, \delta=.92$, and HM Hyperbolic $\left((1+\omega t)^{-1}\right)$ with $\omega=.4$.] 
Table 1: Survey Attributes

\begin{tabular}{|c|c|c|}
\hline Attribute & Definition & Levels \\
\hline Percentage of Basin Cleaned & $\begin{array}{l}\text { The percentage of the Minnesota } \\
\text { River Basin's surface waters having } \\
\text { water quality high enough after the } \\
\text { cleanup is fulfilled to: 1) maintain } \\
\text { healthy, diverse, and successfully } \\
\text { reproducing populations of aquatic } \\
\text { organisms, including invertebrates } \\
\text { such as fish, AND, 2) be suitable for } \\
\text { swimming and other forms of water } \\
\text { recreation. }\end{array}$ & $50 \%, 60 \%, 70 \%$ \\
\hline Cost of the Policy Per Year & $\begin{array}{l}\text { The amount of money that a } \\
\text { household would have to contribute } \\
\text { per year in the form of increased } \\
\text { state income taxes. For each policy, } \\
\text { a household would make five yearly } \\
\text { payments of increased taxes, } \\
\text { beginning immediately this year. }\end{array}$ & $\$ 100, \$ 200, \$ 300$ \\
\hline Time When Cleanup is Fulfilled & $\begin{array}{l}\text { The number of years until the } \\
\text { cleanup is fulfilled to the level of the } \\
\text { policy. The water quality } \\
\text { improvement ends five years after } \\
\text { the cleanup is fulfilled. }\end{array}$ & $0,1,2,3,4,5$ \\
\hline
\end{tabular}


Table 2: (EXAMPLE I) Here is an example of the questions that you will answer. Two policies are presented. For each question, you will select the policy that you prefer. Following the table are descriptions of "Policy A" and "Policy B."

\begin{tabular}{|l|c|c|}
\hline Characteristic & Policy A & Policy B \\
\hline Percentage of Basin Cleaned & $50 \%$ & $70 \%$ \\
\hline Cost of Policy Per Year & $\$ 100$ & $\$ 200$ \\
\hline Time When Cleanup is Fulfilled & Now (2008) & 2 Years From Now (2010) \\
\hline Check the box of the policy you prefer & I prefer Policy A & I prefer Policy B \\
\hline
\end{tabular}

"Policy A" results in 50\% of the Minnesota River Basin's surface waters being cleaned up immediately. The improvement lasts for 5 years. The cost of "Policy A" is $\$ 100$ per year and begins immediately. Your household would have to make five yearly increased tax payments.

Table 3: (EXAMPLE I) Summary of Benefits and Costs for "Policy A"

\begin{tabular}{|l|c|c|c|c|c|c|c|c|c|}
\hline Year & 2008 & 2009 & 2010 & 2011 & 2012 & 2013 & 2014 & 2015 & 2016 \\
\hline Percentage of Basin Cleaned & $50 \%$ & $50 \%$ & $50 \%$ & $50 \%$ & $50 \%$ & $0 \%$ & $0 \%$ & $0 \%$ & $0 \%$ \\
\hline Payment & $\$ 100$ & $\$ 100$ & $\$ 100$ & $\$ 100$ & $\$ 100$ & $\$ 0$ & $\$ 0$ & $\$ 0$ & $\$ 0$ \\
\hline
\end{tabular}

"Policy B" results in 70\% of the Minnesota River Basin's surface waters being cleaned up beginning 2 years from today. The improvement lasts for 5 years after the cleanup is fulfilled. The cost of "Policy B" is $\$ 200$ per year and begins immediately. Your household would have to make five yearly increased tax payments.

Table 4: (EXAMPLE I) Summary of Benefits and Costs for "Policy B"

\begin{tabular}{|l|c|c|c|c|c|c|c|c|c|}
\hline Year & 2008 & 2009 & 2010 & 2011 & 2012 & 2013 & 2014 & 2015 & 2016 \\
\hline Percentage of Basin Cleaned & $0 \%$ & $0 \%$ & $70 \%$ & $70 \%$ & $70 \%$ & $70 \%$ & $70 \%$ & $0 \%$ & $0 \%$ \\
\hline Payment & $\$ 200$ & $\$ 200$ & $\$ 200$ & $\$ 200$ & $\$ 200$ & $\$ 0$ & $\$ 0$ & $\$ 0$ & $\$ 0$ \\
\hline
\end{tabular}


Table 5: Demographics for the Minnesota River Basin Survey and the State of Minnesota

\begin{tabular}{|c|c|c|}
\hline Characteristic & $\begin{array}{l}\text { MRB Survey } \\
\text { Sample }\end{array}$ & $\begin{array}{l}\text { Minnesota } \\
\text { Population }\end{array}$ \\
\hline Median Age & 51.0 & 36.9 \\
\hline (Standard Deviation) & 15.16 & \\
\hline Percent Male & 21.1 & 49.8 \\
\hline (Standard Deviation) & 40.89 & \\
\hline Median Household Income & $\$ 42,500$ & $\$ 55,616$ \\
\hline (Standard Deviation) & $\$ 34,324$ & \\
\hline Percent High School Degree or Higher & 98.3 & 90.7 \\
\hline (Standard Deviation) & 12.93 & \\
\hline Percent Bachelor's Degree or Higher & 34.2 & 30.6 \\
\hline (Standard Deviation) & 47.44 & \\
\hline Percent White & 92.4 & 88.0 \\
\hline (Standard Deviation) & 26.50 & \\
\hline Percent Black or African American & 1.3 & 4.3 \\
\hline (Standard Deviation) & 11.33 & \\
\hline Percent American Indian or Alaska Native & 2.1 & 1.0 \\
\hline (Standard Deviation) & 14.34 & \\
\hline Percent Asian & 2.1 & 3.4 \\
\hline (Standard Deviation) & 14.34 & \\
\hline
\end{tabular}


Table 6: Simulated Maximum Likelihood Results for Specifications I, II, and III

\begin{tabular}{|c|c|c|c|}
\hline Variable / Parameter & I. & II. & III. \\
\hline Mean Improvement*10 & $\begin{array}{l}0.440 * * * \\
(0.0495)\end{array}$ & $\begin{array}{l}0.280 * * * \\
(0.0397)\end{array}$ & $\begin{array}{l}0.287^{* * *} \\
(0.0399)\end{array}$ \\
\hline S.D. Improvement & $\begin{array}{l}0.0499^{* * *} \\
(0.00592)\end{array}$ & $\begin{array}{l}0.0385^{* * *} \\
(0.00433)\end{array}$ & $\begin{array}{l}0.0372^{* * *} \\
(0.0043)\end{array}$ \\
\hline Mean Cost*10 & $\begin{array}{l}-0.0497^{* * *} \\
(0.00396)\end{array}$ & $\begin{array}{l}-0.0383^{* * *} \\
(0.00297)\end{array}$ & $\begin{array}{l}-0.0381^{* * *} \\
(0.00297)\end{array}$ \\
\hline S.D. Cost*10 & $\begin{array}{l}0.0497^{* * *} \\
(0.00396)\end{array}$ & $\begin{array}{l}0.0383^{* * *} \\
(0.00297)\end{array}$ & $\begin{array}{l}0.0381^{* * *} \\
(0.00297)\end{array}$ \\
\hline Mean $\alpha / \gamma$ & $\begin{array}{l}-8.862^{* * *} \\
(1.476)\end{array}$ & $\begin{array}{l}-7.314^{* * *} \\
(0.965)\end{array}$ & $\begin{array}{l}-7.527^{* * *} \\
(0.959)\end{array}$ \\
\hline Exponential $(\delta)$ Mean & $\begin{array}{l}0.887^{* * *} \\
(0.0103)\end{array}$ & & $\begin{array}{l}0.889^{* * *} \\
(0.00986)\end{array}$ \\
\hline Exponential $(\delta)$ S.D. & $\begin{array}{l}0.088^{* * *} \\
(0.0104)\end{array}$ & & \\
\hline $\begin{array}{l}\text { Personal Characteristics } \\
\text { Intercept }\end{array}$ & & $\begin{array}{l}0.872 * * * \\
(0.0345)\end{array}$ & \\
\hline Age & & $\begin{array}{l}-0.00376 \\
(0.00521)\end{array}$ & \\
\hline Income & & $\begin{array}{l}-0.00079 \\
(0.00241)\end{array}$ & \\
\hline Male & & $\begin{array}{l}0.03068 \\
(0.019)\end{array}$ & \\
\hline Education & & $\begin{array}{l}0.00873 \\
(0.00558)\end{array}$ & \\
\hline MRB Resident & & $\begin{array}{l}-0.03797 * \\
(0.0197)\end{array}$ & \\
\hline $\operatorname{Mean}(\hat{\delta})=1 / \widehat{(1+r)}$ & & 0.880 & \\
\hline $\operatorname{Median}(\hat{\delta})=1 / \widehat{(1+r)}$ & & 0.880 & \\
\hline Simulated Log L & -1032.89 & -1072.61 & -1077.9 \\
\hline
\end{tabular}

Note: Asymptotic Standard Errors are given in parenthesis.

* significant at $10 \%,{ }^{* *}$ significant at $5 \%,{ }^{* * *}$ significant at $1 \%$

The t-tests for mean $\delta$ are against 1 . All others are tested against 0 .

Standard Errors of $\alpha / \gamma$ calculated with the delta method 
Table 7: Simulated Maximum Likelihood Results for Specifications IV, V, VI, and VII

\begin{tabular}{|c|c|c|c|c|}
\hline Variable / Parameter & IV & $\mathrm{V}$ & VI & VII \\
\hline Basin Improvement & $\begin{array}{l}0.0526^{* * *} \\
(0.01156)\end{array}$ & $\begin{array}{l}0.0336^{* * *} \\
(0.00273)\end{array}$ & $\begin{array}{l}0.0476^{* * *} \\
(0.00835)\end{array}$ & $\begin{array}{l}0.0334^{* * *} \\
(0.00273)\end{array}$ \\
\hline Cost & $\begin{array}{l}-0.00466^{* * *} \\
(0.00126)\end{array}$ & $\begin{array}{l}-0.00386^{* * *} \\
(0.00027)\end{array}$ & $\begin{array}{l}-0.00383^{* * *} \\
(0.00027)\end{array}$ & $\begin{array}{l}-0.00316^{* * *} \\
(0.0009)\end{array}$ \\
\hline Improvement X Age/1000 & $\begin{array}{l}-0.299^{*} \\
(0.173)\end{array}$ & & $\begin{array}{l}-0.298^{* *} \\
(0.126)\end{array}$ & \\
\hline Improvement X Income/10000 & $\begin{array}{l}0.00170 * \\
(0.00091)\end{array}$ & & $\begin{array}{l}0.00071 \\
(0.00058)\end{array}$ & \\
\hline Improvement X Male & $\begin{array}{l}-0.0802 \\
(0.0625)\end{array}$ & & $\begin{array}{l}-0.0291 \\
(0.0467)\end{array}$ & \\
\hline Improvement X Resident & $\begin{array}{l}0.0390 \\
(0.0512)\end{array}$ & & $\begin{array}{l}0.0148 \\
(0.0366)\end{array}$ & \\
\hline Improvement X Education & $\begin{array}{l}-0.0272 \\
(0.0171)\end{array}$ & & $\begin{array}{c}-0.00724 \\
(0.0119)\end{array}$ & \\
\hline (Cost X Age/1000) & $\begin{array}{l}0.0122 \\
(0.181)\end{array}$ & & & $\begin{array}{l}-0.211 \\
(0.131)\end{array}$ \\
\hline Cost X Income/10000 & $\begin{array}{l}-0.00015 \\
(0.00009)\end{array}$ & & & $\begin{array}{l}-0.00003 \\
(0.00006)\end{array}$ \\
\hline Cost X Male & $\begin{array}{l}0.00749 \\
(0.00636)\end{array}$ & & & $\begin{array}{l}0.00161 \\
(0.00483)\end{array}$ \\
\hline Cost X Resident & $\begin{array}{l}-0.00358 \\
(0.00544)\end{array}$ & & & $\begin{array}{l}-0.00122 \\
(0.00391)\end{array}$ \\
\hline Cost X Education/100 & $\begin{array}{l}0.0304 \\
(0.0188)\end{array}$ & & & $\begin{array}{l}0.0108 \\
(0.0134)\end{array}$ \\
\hline$(\delta)$ Mean & $\begin{array}{l}0.897^{* * *} \\
(0.0115)\end{array}$ & $\begin{array}{l}0.900 \text { *** } \\
(0.0111)\end{array}$ & $\begin{array}{l}0.898^{* * *} \\
(0.0115)\end{array}$ & $\begin{array}{l}0.898^{* * *} \\
(0.0114)\end{array}$ \\
\hline ( $\delta)$ S.D. & $\begin{array}{l}0.108^{* * *} \\
(0.0137)\end{array}$ & $\begin{array}{l}0.109^{* * *} \\
(0.0134)\end{array}$ & $\begin{array}{l}0.109 * * * \\
(0.0136)\end{array}$ & $\begin{array}{l}0.109^{* * *} \\
(0.0136)\end{array}$ \\
\hline Simulated Log L & -1104.28 & -1110.84 & -1107.66 & -1110.46 \\
\hline
\end{tabular}

Note: Asymptotic Standard Errors are given in parenthesis.

* significant at $10 \%,{ }^{* *}$ significant at $5 \%,{ }^{* * *}$ significant at $1 \%$

The t-tests for mean $\delta$ are against 1 . All others are tested against 0 . 
Table 8: Estimation Results for Alternative Discounting Models

\begin{tabular}{|c|c|c|c|}
\hline Variable / Parameter & $\begin{array}{l}\text { Harvey } \\
\text { Hyperbolic }\end{array}$ & $\begin{array}{l}\text { HМ } \\
\text { Hyperbolic }\end{array}$ & $\begin{array}{l}\text { Quasi- } \\
\text { Hyperbolic }\end{array}$ \\
\hline Mean Basin Improvement*10 & $\begin{array}{l}0.450^{* * *} \\
(0.05)\end{array}$ & $\begin{array}{l}0.491^{* * *} \\
(0.0551)\end{array}$ & $\begin{array}{l}0.444 * * * \\
(0.0526)\end{array}$ \\
\hline S.D. Basin Improvement & $\begin{array}{l}0.0507^{* * *} \\
(0.00588)\end{array}$ & $\begin{array}{l}0.0559^{* * *} \\
(0.00635)\end{array}$ & $\begin{array}{l}0.0496^{* * *} \\
(0.00595)\end{array}$ \\
\hline Mean Cost*10 & $\begin{array}{l}-0.0485^{* * *} \\
(0.00373)\end{array}$ & $\begin{array}{l}-0.0502^{* * *} \\
(0.00387)\end{array}$ & $\begin{array}{l}-0.0501^{* * *} \\
(0.00416)\end{array}$ \\
\hline S.D. Cost*10 & $\begin{array}{l}0.0485^{* * *} \\
(0.00373)\end{array}$ & $\begin{array}{l}0.0502^{* * *} \\
(0.00387)\end{array}$ & $\begin{array}{l}0.0501^{* * *} \\
(0.00416)\end{array}$ \\
\hline Mean $\alpha / \gamma$ & $\begin{array}{l}-9.279^{* * *} \\
(0.94)\end{array}$ & $\begin{array}{l}-9.775^{* * *} \\
(0.992)\end{array}$ & $\begin{array}{l}-8.849^{* * *} \\
(0.994)\end{array}$ \\
\hline Harvey $(\mu)$ Parameter Mean & $\begin{array}{l}0.459^{* * *} \\
(0.0408)\end{array}$ & & \\
\hline Harvey $(\mu)$ Parameter S.D. & $\begin{array}{l}0.350^{* * *} \\
(0.0415)\end{array}$ & & \\
\hline Mean of $\ln (\omega)$ & & $\begin{array}{l}-1.858^{* * *} \\
(0.165)\end{array}$ & \\
\hline S.D. of $\ln (\omega)$ & & $\begin{array}{l}1.609^{* * *} \\
(0.208)\end{array}$ & \\
\hline Mean of $\ln (\beta)$ & & & $\begin{array}{l}0.0947 \\
(0.106)\end{array}$ \\
\hline S.D. of $\ln (\beta)$ & & & $\begin{array}{l}0.288 \\
(0.194)\end{array}$ \\
\hline Mean of $\ln (\delta)$ & & & $\begin{array}{l}-0.129^{* * *} \\
(0.0131)\end{array}$ \\
\hline S.D. of $\ln (\delta)$ & & & $\begin{array}{l}0.0889^{* * *} \\
(0.0108)\end{array}$ \\
\hline Simulated Log L & -1052.36 & -1043.83 & -1031.96 \\
\hline
\end{tabular}

Note: Asymptotic Standard Errors are given in parenthesis.

* significant at $10 \%,{ }^{* *}$ significant at $5 \%,{ }^{* * *}$ significant at $1 \%$ Standard Errors of $\alpha / \gamma$ calculated with the delta method 
Table 9: Point Estimates of Mean, Median, and Standard Deviation of $(\omega)$ and $(\beta)$ and $(\delta)$ Parameters from Table 8

\begin{tabular}{l||ccc}
\hline \hline & Median & Mean & Std. Dev. \\
Parameter & 0.156 & 0.3488 & 0.6975 \\
\hline \hline HM $(\omega)$ & 1.099 & 1.270 & 0.7334 \\
Quasi-Hyperbolic $(\beta)$ & 0.879 & 0.919 & 0.2801 \\
Quasi-Hyperbolic $(\delta)$ & & & \\
\hline \hline
\end{tabular}

Table 10: MWTP for Immediate and 5 Year Delayed Cleanups for Alternative Discounting Models

\begin{tabular}{l||ccc}
\hline \hline & Harvey & HM & Q-H \\
\hline \hline MWTP Immediate Cleanup & $\$ 30.97$ & $\$ 38.36$ & $\$ 37.30$ \\
MWTP Cleanup Delayed 5 Years & $\$ 18.05$ & $\$ 23.62$ & $\$ 19.98$ \\
\hline \hline
\end{tabular}

